\title{
Circulation of Power During Braking of Tyre of Vehicle Wheel On Support Rollers of he Diagnostic Stand
}

\author{
Fedotov Aleksandr I. \\ doctor of technical Sciences \\ Department "Automobile transport" \\ Irkutsk national research technical University \\ 664074, Irkutsk, Lermontov str., 83 \\ e-mail: fai@istu.edu
}

\author{
Krivtsov Sergey N. \\ doctor of technical Sciences \\ Department "Automobile transport" \\ Irkutsk national research technical University \\ 664074, Irkutsk, Lermontov str., 83 \\ e-mail: krivcov_sergei@mail.ru
}

\author{
Yankov Oleg S. \\ candidate of technical Sciences \\ Department "Automobile transport" \\ Irkutsk national research technical University \\ 664074, Irkutsk, Lermontov str., 83 \\ e-mail:066813@mail.ru
}

\begin{abstract}
The article conducts the study of the circulation of power in the diagnosis of the car on the brake stand that is kinematically connected with the supporting rollers. Case study. It is suggested that the longitudinal displacement of the wheel operating in braking mode on two kinematically connected support rollers leads to kinematical misalignment, resulting in circulation of the parasitic power of the $N_{C}$ in a closed loop "tyre - front support roller - chain transmission - rear support roller tyre". Research result. The conditions of the circulating power flow are revealed experimentally, which are explained by the fact that during the braking of the wheel with an elastic tire on the kinematically connected support rollers of the stand, as a result of kinematical misalignment, there is circulation of the parasitic power of the $\mathbf{N}_{C}$ in a closed loop "tire - front support roller chain transmission - rear support roller - tire". Conclusion. It is found that the circulation of parasitic power is formed regardless of the presence of the displacement of the wheel, but varies depending on the variation of the displacement value $a$ and the normal load $G_{K}$ on the wheel. The occurrence of circulating parasitic power $\mathrm{N}_{\mathrm{C}}$ occurs in the driven mode of rolling the wheel, when $S=0$ it increases to a value $S=0,1$, upon reaching which it falls. The magnitude of spurious circulating power $N_{C}$ takes a minimum value when the slippage is $S \geq 0,7$. It is established that the circulating power values $\mathrm{N}_{\mathrm{C}}$ can be commensurate with the value of the braking power $\mathbf{N}_{\mathrm{T}}$.
\end{abstract}

Keywords - diagnosis, power, wheel radius, wheel slip, the coefficient of friction, normal reaction, tangential response, kinematic misalignment, the bearing rollers of the diagnostic stand, elastic tire, the circulating power.

\section{INTRODUCTION}

Currently, as a rule, the control of the technical condition of the car brake systems under operating conditions is carried out by the bench method. One of the advantages of the bench method is the realization of the principle of reversibility of motion $[6,7]$. The results of bench testing do not always give reliable information about the technical condition of the car brake system $[1,5]$. This is largely due to the peculiarities of the mechanics of elastic tire interaction with the cylindrical support surfaces of the rollers, as well as the peculiarities of the test modes of control of the technical condition of the car brake systems on the stands.

First, the initial braking speed of the vehicle in bench conditions is much lower than in operating conditions. Secondly, when setting the car on the rollers of the stand, there is a non-parallelism of the axes of its wheels and the axis of the stand. Third, in road conditions, the vehicle's tyres are in contact with the flat bearing surface and have one contact spot each. For bench control in each of the wheels of the car contact two, and, moreover, with the cylindrical surfaces of the rollers of the stand. Fourth, when braking the wheels on the stand, under the influence of braking forces occurs longitudinal displacement of the wheel center of rotation relative to the axis of symmetry of the support rollers.

Since the longitudinal displacement of the braking wheel affects the shape and size of the spots of its contacts and changes in the kinematic and power parameters of the tires, this significantly affects the results of bench control of the braking systems of cars. Therefore, the study of the mechanics of the interaction of elastic tire braking car wheel with cylindrical surfaces of two kinematically connected, support rollers of the stand should be considered relevant. 


\section{ANALYSIS OF PROBLEM}

Let us consider the process of braking the car wheel tire on two kinematically connected support rollers stand by the example of the scheme shown in Fig. 1.

Wheel tyre 2 , mounted on two kinematically connected by chain transmission 5 support rollers 3 and 4 , touches the treadmill surface rollers, forming two identical contact spots. With the fixed wheel 2 and the support rollers 3 and 4 , normal reactions $R_{Z 1}$ and $R_{Z 2}$ occur in the tire contact spots. In the course of braking the wheel, under the action of the brake torque $M_{T}$ in the tire contact spots with the support rollers 3 and 4 , there are tangential reactions $R_{X 1}$ and $R_{X 2}$. And since the support rollers 3 and 4 are connected to each other by chain transmission 5, a closed loop is formed "tire - rear support roller - chain transmission - front support roller - tire" [2].

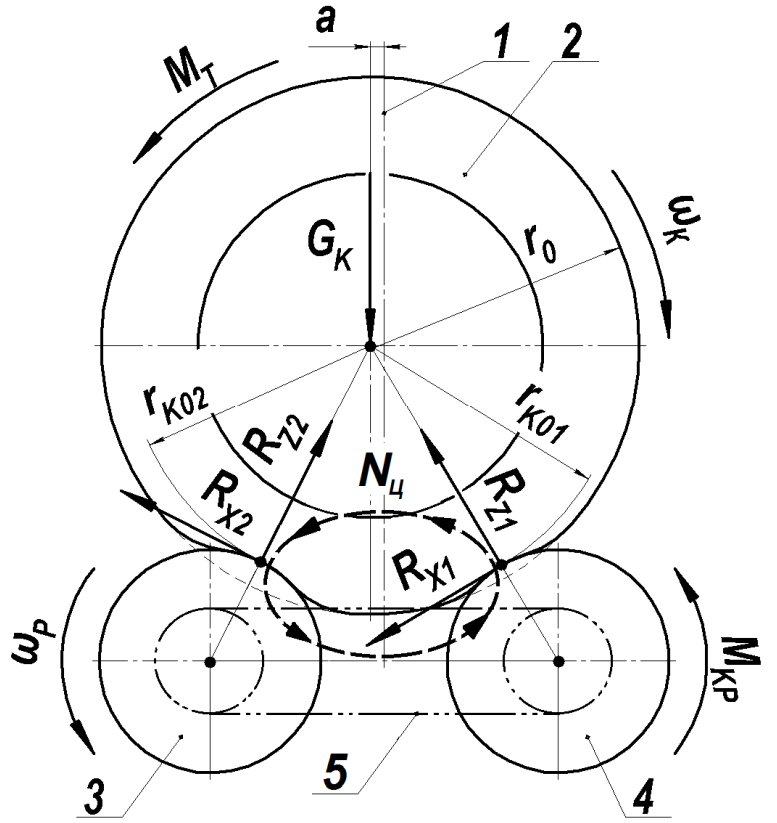

Fig. 1. Diagram of the braking process, the wheel is kinematically connected to the two support rollers of the diagnostic stand:

1 - the axis of symmetry of the support roller; 2 - wheel; 3 - rear support roller; 4 - the front support roller; 5 - chain transfer, a is the offset of the wheel; $\omega_{K}-$ is the angular frequency of rotation of the wheel; $\omega_{P}-$ is the angular frequency of rotation of rollers; $G_{K}$ - normal load applied to the wheel; $r_{0}$ - the radius of the free wheel; $r_{K O I}$ - rolling radius of wheel on the front roller; $r_{K 02}$ - rolling radius of wheel on the rear roller; $M_{T}$ - braking torque; $R_{Z I}$ is a normal reaction at the front roller; $R_{X 1}$ - tangential reaction on the front roller; $R_{Z 1}$ normal reaction on the rear roller; $R_{X 2}$ - tangential reaction on the rear roller; $N_{C}$ - parasitic power circulating in a closed loop "tire - rear support roller - chain transmission - front support roller-tire".

Before the start of braking, the wheel operates in the slave mode, the tyre slip is absent $(S=0)$, the tangential reactions $R_{X I}$ and $R_{X 2}$ are approximately equal to each other and (if you neglect the rolling resistance force) are zero:

$$
R_{X 1}=R_{X 2}=0 .
$$

The normal reaction on the front and rear roller stand equal to each other:

$$
R_{\mathrm{Zl}}=R_{\mathrm{Z2}} \text {. }
$$

In addition, the power radii of the wheel (rolling radii of the wheel in the slave mode) are equal to the elastic tire on the front and rear roller of the stand:

$$
r_{K 01}=r_{K 02 .} .
$$

At the initial braking torque, the slip increases $(S>0)$. There is a displacement of the treadmill to the side of the rear support roller and the growth of reactions on it, as well as a decrease in reactions on the front support roller. The power radius of the wheel $r_{K O I}$ on the front roller 4 becomes greater than the power radius $r_{K 02}$ on the rear roller 3 .

The inequality of power radiuses $r_{K O 1} r_{K O 2}$ leads to kinematic misalignment in a closed loop "tire-rear support roller-chain transmission-front support roller-tire" resulting in a slip difference $\Delta S$ tires in the spots of contact with the front and rear rollers, which affects the amount of the realized coefficient of adhesion $\varphi$ (Fig. 2).

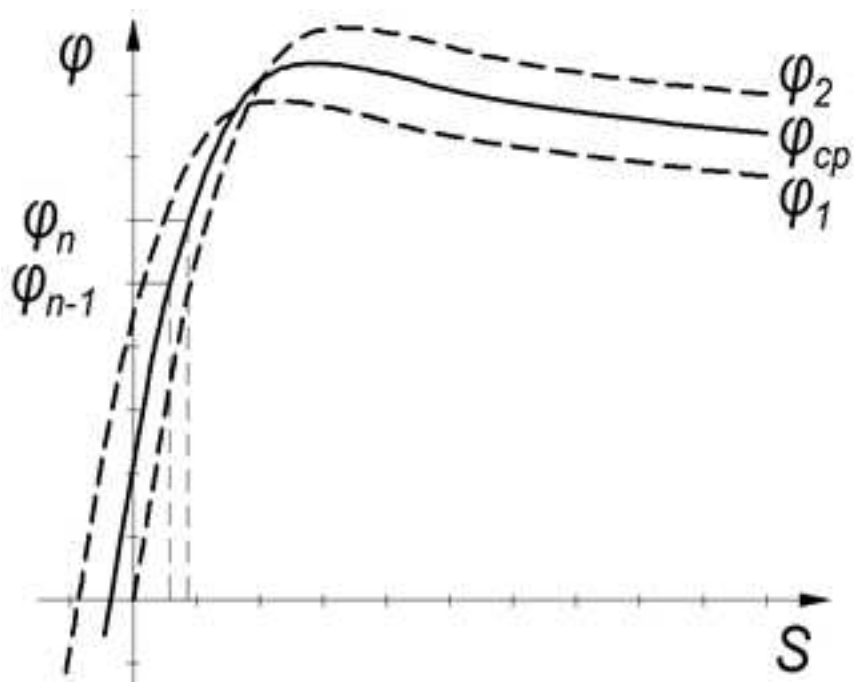

Fig. 2. A graph of coefficients of adhesion $\varphi 1$ on the front roller, $\varphi 2$ on the rear roller and the average value $\varphi$ avg on the magnitude of slip $\mathrm{S}$

The inequality of power radii $r_{K O 1} \neq r_{K O 2}$ is accompanied by a difference in the values of the forces of pressing the treadmill to the surface of the front 4 or rear 3 support rollers (Fig. 1), resulting from the support rollers are unequal values for normal reaction $R_{Z 1} \neq R_{Z 2}$. Inequality normal reactions $R_{Z 1} \neq$ $R_{Z 2}$ in the braking process, the wheel forms a tangent inequality of implemented reactions $R_{X 1} \neq R_{X 2}$, which leads to strength, circulating in a closed contour "tire - rear roller chain drive - front roller bearing - tire" [2].

Kinematic misalignment leads to the fact that in a closed loop "tire-rear support roller-chain transmission-front support roller-tire" (Fig. 1) the flow of the parasitic power of the $N_{C}$ begins to circulate, affecting the values of the realized coupling coefficients $\varphi_{1}$ on the front roller and $\varphi_{2}$ on the rear roller (Fig. 2), 
The value of this power can be defined as:

$$
N_{L}=\Delta R_{X} \cdot V_{T} ;
$$

where $\Delta R_{X}$ is the force circulating in a closed loop, $[\mathrm{N}]$;

$V_{T}$ is the portable surface speed of the treadmill, [m/s].

The value of the force circulating in the closed loop can be determined on the basis of the expression:

$$
\Delta R_{X}=R_{\text {Zavg }} \cdot \Delta \varphi
$$

where $R_{\text {Zavg }}$ is the mean of the normal reaction, [N];

$\Delta \varphi$ - the difference between the realized coefficients of adhesion.

The average value of the normal reaction $R_{\text {Zavg }}$ is determined by the formula:

$$
R_{\mathrm{Zcp}}=\frac{R_{\mathrm{Z} 1}+R_{\mathrm{Z} 2}}{2}
$$

where $R_{Z 1}$ and $R_{Z 2}$ are normal reactions on the front and rear support rollers of the stand, $[\mathrm{N}]$.

The difference between the coupling coefficients $\Delta \varphi$, arising from kinematic misalignment, is calculated by the formula:

$$
\Delta \varphi=\varphi_{\text {avgn }}-\varphi_{\text {avgn-1 }}
$$

where $\varphi_{\text {avg }}-$ the average value of the coefficient of adhesion (Fig. 2).

Determination of the average value of the coefficient of friction $\varphi_{a v g}$ (Fig. 2) is carried out according to the formula:

$$
\varphi_{\text {avg }}=\frac{\varphi_{1}+\varphi_{2}}{2}
$$

where $\varphi_{1}$ - the value of the coefficient of friction of the tire with the front roller;

$\varphi_{2}-$ the value of the coefficient of friction of the tire with a rear roller.e.

\section{RESEARCH METHODS}

To plot the dependence of the circulating power of the $N_{C}$ on the slip $S$, experimental studies were carried out at the beginning without the initial displacement of the wheel a, and then with the displacement $(a=15 \mathrm{~mm})$ of the wheel towards the front, and with the displacement $(a=15 \mathrm{~mm})$ towards the rear support roller (Fig. 1).

The Amtel $175 / 75-R 13-82 H$ tyre, the tread wear was $5 \%$, the air pressure was monitored throughout the experimental study and maintained at the level of $p_{W}=0.21 \mathrm{MPa}$. The normal load on the wheel was set to $G_{K}=3250 \mathrm{~N}$. The initial braking speed $V_{T}$ was set in the same way as the speed at which the brake system is carried out control car bench method, and is $V_{T}=1,1 \mathrm{~m} / \mathrm{s}$.

The research was carried out on a specially designed and manufactured unique stand [3, 4], which implements the principle of measuring the force parameters of the elastic tire interaction with the support rollers based on the measurement of the elementary normal $\Delta R_{Z}$ and tangential $\Delta R_{X}$ reactions distributed over the lengths of the contact spots $l_{d}$ of the tested tire with surfaces of cylindrical support rollers.
For an objective assessment of the circulating power $N_{C}$, let us determine the power consumed by the braking process $N_{T}$ :

$$
N_{T}=F_{T} \cdot V_{T}
$$

where $F_{T}$ is the realized braking force, [N].

To assess the value of circulating power $N_{C}$ in relation to the maximum power required for the braking process $N_{T \max }$ determine the percentage $\Delta_{N}$ :

$$
\Delta_{N}=\frac{N_{L} \cdot 100}{N_{T \max }} ;
$$

where $N_{\max }$ is the maximum power consumed by the braking process, $[\mathrm{W}]$.

\section{THE RESUlTS OF THE STUDY AND THEIR ANALYSIS}

The results of the study of the circulating power of the $N_{C}$ depending on the displacement of a wheel $a$ are presented in Fig. 3-5.

Analysis of the graphs shown in Fig. 3-5 allows to draw the following conclusions. When braking a wheel with an elastic tire on kinematically closed rollers of the stand when it is loaded with a normal load $G_{K}=3250 \mathrm{~N}$ in a closed circuit "tire-rear support roller-chain transmission-front support roller-tire" there is a circulation of power $N_{C}$ regardless of the magnitude and direction of displacement a wheel.

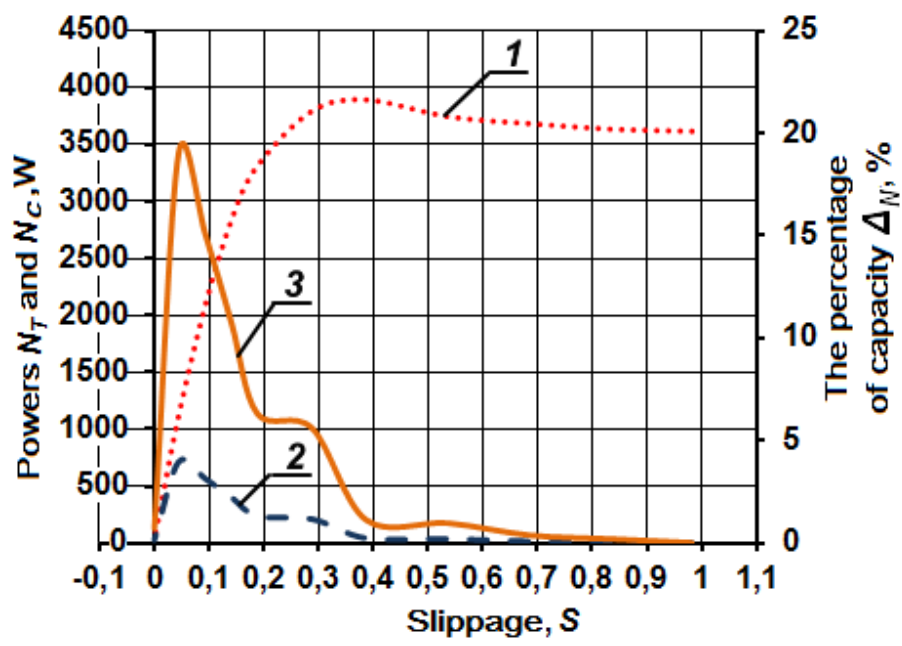

Fig. 3. Schedule changes the circulating power NC, the power required for the braking process NT and percentage of circulating power $\Delta \mathrm{N}$ of the average slip $\mathrm{S}$ at normal load $\mathrm{GK}=3250 \mathrm{~N}$ without displacement of the wheel $(\mathrm{a}=0)$ :

1 - power required for the braking process $N_{T} ; 2$ circulating power $N_{C} ; 3$ - the percentage of the circulating power to the maximum value of the power required for braking $\Delta_{N}$

In the case where the wheel is installed without the initial displacement, the circulating power is $N_{L}=712.2 \mathrm{~W}$ with an average slip $S=0.044$ (Fig. 3). The maximum value of the percentage of circulating power $N_{C}$ to the maximum value of the power required for the inhibition of $N_{T}$ is $\Delta_{N}=19.02 \%$ in the value of the average $\operatorname{slip} S=0.044$. 


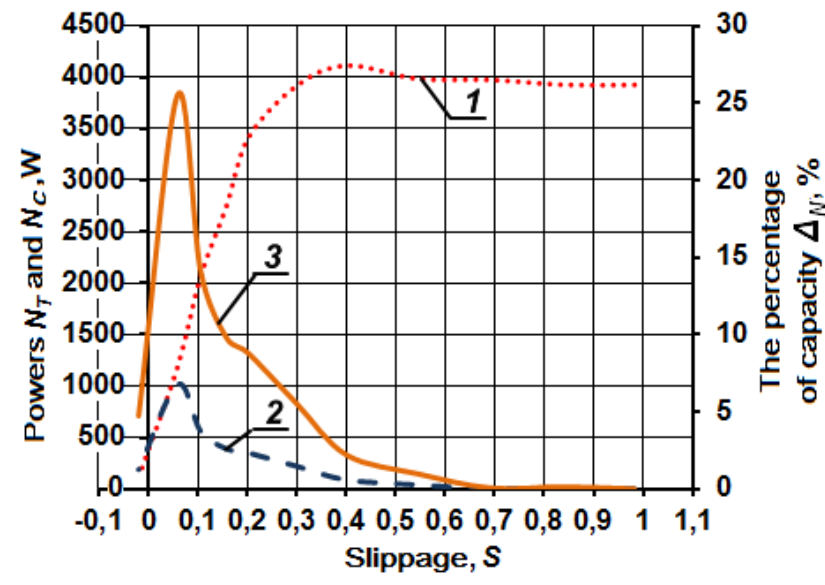

Fig. 4. Schedule changes the circulating power NC, the power required for the braking process NT and percentage of circulating power $\Delta \mathrm{N}$ of the average slip $\mathrm{S}$ at normal load $\mathrm{GK}=3250 \mathrm{~N}$ offset wheels in the front roller $(\mathrm{a}=15 \mathrm{~mm})$ :

1 - power required for the braking process $N_{T} ; 2$ circulating power $N_{C} ; 3$ - the percentage of the circulating power to the maximum value of the power required for braking $\Delta_{N}$

The maximum value of $N_{C}=1014.1 W$ at wheel displacement $a=15 \mathrm{~mm}$ in the direction of the front support roller circulating power reaches an average slip $S=0.058$ (Fig. 4). The maximum value of the percentage of circulating power $N_{C}$ to the maximum value of the power required for the inhibition of $N_{T}$ is $\Delta_{N}=25.51 \%$ when the value of the average $\operatorname{slip} S=0.058$.

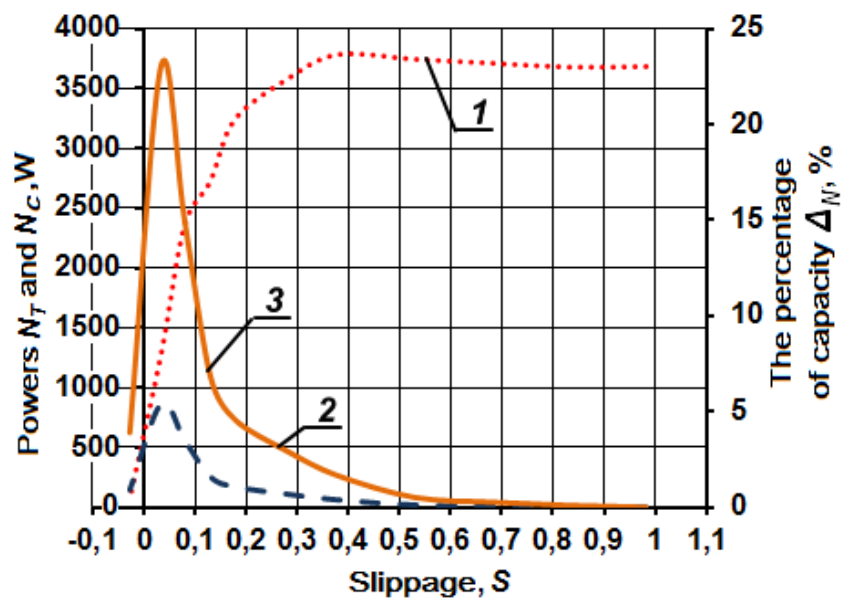

Fig. 5. Schedule changes the circulating power NC, the power required for the braking process NT and percentage of circulating power $\Delta \mathrm{N}$ of the average slip $\mathrm{S}$ at normal load $\mathrm{GK}=3250 \mathrm{~N}$ offset wheels in the rear roller $(\mathrm{a}=15 \mathrm{~mm})$ :

1 - power required for the braking process $N_{T} ; 2$ circulating power $N_{C} ; 3$ - the percentage of the circulating power to the maximum value of the power required for braking $\Delta_{N}$

The displacement of the wheels towards the rear of the roller, the value of circulating power $N_{C}$ is $N_{C}=863.4 \mathrm{~W}$ with the average slip $\mathrm{S}=0.033$ (Fig. 5). The maximum value of the percentage of circulating power $N_{C}$ to the maximum value of the power required for the inhibition of $N_{T}$ is $\Delta_{N}=23.05 \%$ in the value of the average slip $S=0.033$.

The flow of the circulating power of the $N_{C}$ in all three cases decreases with an increase in slippage and approaches zero at an average slippage of $S=0.7$.

\section{CONCLUSION}

The braking of the wheel on two kinematically connected support rollers is accompanied by the circulation of the $N_{C}$ power in a closed loop "tyre - rear support roller - chain transmission - front support roller - tyre". The flow of circulating power $N_{C}$ occurs regardless of the displacement of the wheel relative to the support rollers of the stand. The occurrence of circulating power $N_{C}$ occurs at the time of rolling of the wheels in slave mode. As the braking torque increases and the slip increases to $S=0.05$, the value of the circulating power of the $N_{C}$ grows rapidly. To achieve the slip $S=0.05$ and is a smooth drop in circulating power $N_{C}$. Then it decreases with increasing slip and approaches zero with slipping $S=0.7$, which is close to the critical slip of the stationary coupling characteristics of the tire with the cylindrical rollers of the stand. When braking the wheel with no initial bias, the percentage of circulating power $N_{C}$ and maximum power expended on braking $N_{\text {Tmax }}$ is $\Delta_{N}=19.02 \%$ in the value of the average slip $S=0.044$.

When an offset wheel and change values of circulating power $N_{C}$. The displacement of the wheel toward the front castors, the percentage of circulating power $N_{C}$ and maximum power expended on braking $N_{\operatorname{Tmax}}$ is $\Delta_{N}=25.51 \%$ when the value of the average slip is $S=0.058$. The displacement of the wheel in the direction of rear support roller, the percentage of circulating power $N_{C}$ and maximum power expended on braking, $N_{T}$ is $\Delta_{N}=23.05 \%$ in the value of the average slip $\mathrm{S}=0.033$. High percentages $\Delta_{N}$ and $\Delta_{N \max }$ indicate that at the beginning of braking, when the mean slip $S$ is approximately zero, the circulating power of the $N_{C}$ in more than a quarter may exceed the value of the braking power $N_{T}$.

\section{References}

[1] A.V. Boyko, Improving diagnostic method for auto-mobiles brake systems in operation at power stands with running drums, dissertation of the candidate of technical sciences, Irkutsk, 2008. pp. 281.

[2] A.V. Boyko, A.I. mFedotov, D. Zogt "Experimental investigation of forces of rolling resistance the car's wheels on rollers stand", Bulletin of the Irkutsk State Technical University, vol. 8 (55), pp. 115-120, 2011.

[3] A.V. Boyko, O.S. Yankov, A.S. Markov "A bench for studying the process of interaction of an elastic tire with support surfaces", Collection of the International scientific-practical conference "Transport systems of Siberia. Development of the transport system as a catalyst for the growth of the state economy", International Scientific and Practical Conference, Siberian Federal University, pp. 297-303, april 7-8, 2016.

[4] A.V. Boyko, O.S. Yan'kov, A.S. Markov, N.Yu. Kuznetsov "A bench for studying the process of interaction of an elastic tire with two running drums", Materials of the 90th International Scientific and Technical Conference "A Car for Siberia and the Far North. Construction, Exploitation, Economics", pp. 115-123, April 9-10, 2015.

[5] A.I. Fedotov, A.V. Boyko, A.S. Potapov "On the repeatability of measurements of the parameters of the braking process of a car on a stand with running drums", Bulletin of the Irkutsk State Technical University, vol 1 (33), pp. 63-71, 2008. 
[6] A.I. Fedotov Technology and the organization of diagnostics at service support: the textbook for stud. Institutions of higher education, Education M.: Publishing Center “Academy”, 2015.
[7] A.I. Fedotov Diagnosis of the car: a textbook for university students studying in the direction of training bachelors and masters "Operation of transport-technological machines and complexes", Irkutsk State Technical University, Irkutsk, 2012. 